\title{
Patrimonio Cultural Inmaterial: un estudio de los criterios y límites de su definición jurídica en la legislación española
}

\author{
Pablo H. Velasco Quintana ${ }^{a}$
}

${ }^{a}$ Universidad CEU San Pablo, C/Julián Romea 18, 28003, Madrid. pvelasco@ceu,es

\begin{abstract}
Resumen
El Patrimonio Cultural Inmaterial está regido en España por la Convención UNESCO para la salvaguardia de 2003, la Ley estatal 1/2015 y las legislaciones autonómicas que contienen referencias a este patrimonio. En estos textos legales se encuentra la definición, criterios y límites para poder delimitar un concepto amplio y cambiante. Pese a su fragilidad, el patrimonio cultural inmaterial es un importante factor del mantenimiento de la diversidad cultural frente a la creciente globalización. La comprensión del patrimonio cultural inmaterial de diferentes comunidades contribuye al diálogo entre culturas y promueve el respeto hacia otros modos de vida.
\end{abstract}

Palabras clave: patrimonio cultural inmaterial, colisión de derechos, Convención UNESCO 2003, definición patrimonio cultural inmaterial.

\begin{abstract}
Intangible Cultural Heritage is governed in Spain by the UNESCO Convention of 2003, Law 1/2015 and the regional laws that contain references to this kind of heritage. In these legal texts are included the definition, criteria and limits to be able to define a broad and changing concept. While fragile, intangible cultural heritage is an important factor in maintaining cultural diversity in the face of growing globalization. An understanding of the intangible cultural heritage of different communities helps with intercultural dialogue, and encourages mutual respect for other ways of life.
\end{abstract}

Keywords: intangible cultural heritage, UNESCO Convention 2003, intangible cultural heritage definition, collision of rights. 


\section{Introducción: un concepto jurídico amplio y, por tanto, necesitado de limitación}

El pasado 11 de marzo de 2020, Ximo Puig, anunciaba la suspensión de la celebración de las Fallas de Valencia, manifestación cultural que forma parte del patrimonio cultural inmaterial de la humanidad, debido al protocolo de contención del coronavirus COVID2019. Este hecho mostraba claramente que, a pesar de la importancia y arraigo social y cultural del patrimonio cultural inmaterial, este no es ilimitado y debe plegarse a otros bienes jurídicos que sean más relevantes.

El desarrollo de los estudios de la Antropología Social respecto del Patrimonio Cultural ha supuesto un camino que nos lleva a considerarlo como un sistema social complejo formado por muchas y muy diferentes manifestaciones. La protección jurídica ha precisado un concepto más amplio. Se necesita recoger los valores, la ética, la costumbre social, las creencias, los mitos expresados de manera sensible y en soportes en ocasiones materiales, o en ocasiones efímeros.

Patrimonio Inmaterial, Patrimonio Intangible, Patrimonio Vivo, son algunos de los términos utilizados para referirse a esa realidad que es fuente de identidad, creatividad y diversidad de los pueblos.

Un concepto amplio y quizá, como consecuencia de ello, demasiado vago. Debemos plantear también en este momento el por qué, la necesidad de proteger un patrimonio semejante.

"Creo, en efecto, que el derecho debe proteger el folclore, porque éste es una parte importante de la cultura, la parte más viva de la cultura y un núcleo fundamental de las culturas iberoamericanas, aunque cada vez más con menos peso en las sociedades europeas porque precisamente no hemos sabido protegerlo. Lo cierto es que en la preservación de las culturas tradicionales nos estamos jugando el humus en el que se desarrolla y crece la diversidad y que da a lugar a esa multiplicidad de modos irrepetibles de ser humanos" (Prieto, 2002).

Desde la Segunda Guerra Mundial el organismo internacional UNESCO ha desarrollado una intensa actividad dirigida a la protección del patrimonio cultural material, que ha ido evolucionando y a la que se ha añadido dos categorías más: el patrimonio natural y el inmaterial.

Ha sido este organismo internacional el que ha iniciado un programa de protección específico para este patrimonio y además ha propuesto un concepto idóneo para delimitar nuestro objeto.

Esta institución sumada al desarrollo de la Antropología Social y el desarrollo del concepto de cultura han supuesto dos grandes bases para la afirmación del Patrimonio Inmaterial.

Como afirma Carrera Díaz, el concepto de Patrimonio Cultural es una construcción social, cambiante y dinámica que ha ido evolucionando progresivamente desde su nacimiento en el siglo XVIII como instrumento para enaltecer los recién nacidos Estados Nación, iluministas y racionalistas reflejando el poder de sus élites ilustradas, hasta la actualidad (Carrera, 2009). A lo largo de este devenir y como tal constructo social, ha sufrido importantes transformaciones que reflejan los cambios sociales, políticos y culturales acontecidos a nivel global.

\section{Convención UNESCO para la Salvaguardia del Patrimonio Cultural Inmaterial de 2003. Criterios y límites}

En el artículo $2^{\circ}$ de la Convención encontramos la definición del objeto de estudio del presente trabajo. Se trata de, como afirma López Bravo (López, 2004), una definición en tres pasos: primero qué es el patrimonio inmaterial en sentido estricto; después, los instrumentos y espacio que le son inherentes; y por último un criterio de reconocimiento y autorreferencialidad.

"Los usos, representaciones, expresiones, conocimientos y técnicas -junto con los instrumentos, objetos, artefactos, y espacios culturales que le son inherentes- que las comunidades, los grupos y en algunos casos los individuos reconozcan como parte integrante de su patrimonio cultural" 
Como afirma el Plan Nacional de Salvaguarda del Patrimonio Cultural Inmaterial del Ministerio de Cultura español, se trata de una buena definición por dos razones: "primera porque ha sido ampliamente debatida y consensuada por expertos de ámbitos diversos en el plano internacional y segunda por el hecho de que España ratificara dicha Convención en el año 2006".

\subsection{Características y criterios definitorios del Patrimonio Inmaterial}

UNESCO también subraya algunos puntos del concepto:

a. Es tradicional, contemporáneo y viviente a un mismo tiempo, ya que integra tradición y costumbres contemporáneas ${ }^{1}$. Es un patrimonio vivo. Imbricado en las formas de vida. Interconectado con muchos ámbitos de la vida cotidiana.

En palabras de Koichiro Matsuura (Roque, 2013), exdirector general de la UNESCO: "El patrimonio no es solamente sede de la memoria de la cultura de ayer, sino también el laboratorio donde se inventa el mañana”.

b. Es representativo, al estar integrado por bienes culturales cuyo valor reside en su exclusividad y en la responsabilidad de los miembros de cada comunidad en la transmisión de los mismos de generación en generación y a otras comunidades. Representa "la memoria viva de la comunidad cuando remite a acontecimientos o conocimientos considerados fundamentales de su historia. El proceso de rememoración no está fosilizado, sino expuesto a selecciones y redefiniciones a propósito de episodios del pasado, que en el PCI son confirmadas y revitalizadas por la comunidad en el presente. Por tanto, este tipo de Patrimonio se caracteriza por depender de los acuerdos, llevados a cabo por las personas portadoras de la tradición, quienes determinarán que seguir recordando y qué no" (Plan Nacional, 2011). Este patrimonio depende de los conocimientos, técnicas, tradiciones y costumbres que se transmiten en esa comunidad.

c. Está basado en la comunidad, pues sólo será verdadero patrimonio si es reconocido como tal por las comunidades. Se sustenta en la comunidad, "como conjunto de individuos que lo crean, mantienen y transmiten, y sin cuyo reconocimiento nadie puede decidir que una expresión o un uso concreto forma parte de su patrimonio". Así, se trata de manifestaciones culturales que son "vividas doblemente: en primer lugar, por parte de cada persona, desde el punto de vista subjetivo, es decir desde la perspectiva del "yo". En segundo lugar, por parte de cada cual, como miembro indiferenciado de la comunidad, es decir, desde la perspectiva del "nosotros" comunitario. La primera perspectiva remite a la biografía individual y la segunda a la colectiva" (Plan Nacional, 2011).

\section{Ley 10/2015 de 26 de mayo para la salvaguarda del Patrimonio Cultural Inmaterial. Definición, criterios y límites}

Concepto de patrimonio cultural inmaterial aparece en el artículo 2 de la ley. Aquí encontramos la definición seguida de una lista abierta que contiene además una serie de ligeras innovaciones respecto de la definición de la Convención UNESCO.

"Es interesante la utilización ya más común del adjetivo "cultural” por "histórico" o "artístico", como bien apunta Vaquer: El ámbito de la legislación de patrimonio histórico sigue vivo y ha dejado obsoleta su reconducción al ámbito de la cultura material. Acaso estamos asistiendo a la paulatina conversión del régimen del patrimonio histórico-artístico en un régimen general o común del patrimonio cultural. De hecho, desde que la ley vasca en la materia, de 1990, optó por la denominación oficial de "Ley de Patrimonio

\footnotetext{
${ }^{1}$ Culle Murphy, en un artículo publicado en el The Atlantic Monthly, en septiembre de 2001, sobre la campaña de Alfonso Pecoraro Scanio para declarar la pizza como patrimonio mundial, encontraba la lista de UNESCO como algo que lograba impresionar: "impresiona tanto como la programación de la televisión pública a las 3 de la mañana". Murphy con mucha ironía propuso algunos candidatos para la siguiente lista: como el fin de semana, las mentiras piadosas, y la voz pasiva. Esta ironía indica el proceso por el que la vida se convierte en patrimonio y los contemporáneos (los del presente que son valorados por su dimensión pasada) se convierten en contemporáneos (los del presente que se relacionan con su pasado como patrimonio). El artículo titulado Inmaterial civilization se puede consultar en http://www.theatlantic.com/magazine/archive/2001/09/immaterialcivilization/376426/ Última consulta el 7/10/2015.
} 
Cultural", y no "Histórico", han adoptado también esta denominación las leyes de Cataluña, Galicia, Comunidad Valenciana, Cantabria, Aragón y Castilla y León” (Vaquer, 2005)

De este modo el Patrimonio Cultural Inmaterial está compuesto por "los usos, representaciones, expresiones, conocimientos y técnicas que las comunidades, los grupos y en algunos casos los individuos, reconozcan como parte integrante de su patrimonio cultural". Así se define un patrimonio por las características de sus propios bienes que lo conforman (usos, representaciones, expresiones, conocimientos y técnicas), por el sujeto que lo ostenta (comunidades, grupos o individuos) y por la consciencia del propio sujeto respecto del bien (reconocimiento como parte de su patrimonio) $)^{2}$.

En relación a la definición que hace la convención UNESCO, podemos decir que sigue su mismo patrón, aunque encontramos diferencias:

a. En la ley española no hay mención explícita en la definición a los bienes materiales inherentes a los bienes inmateriales. Solo más adelante, la ley dedica el artículo 4 a la protección de esos bienes materiales asociados y se menciona concretamente que se protegerán según el caso concreto partiendo de la ley 16/1985 del Patrimonio Histórico español y de las leyes autonómicas. Este punto puede suponer un peligro de que el Estado se otorgue competencias sobre bienes muebles e inmuebles localizados en territorios de las Comunidades Autónomas (Carrera Díaz, 2015, p. 23).

b. La Convención además aprovecha la definición para incluir algunos criterios que no aparecen en la ley española, como por ejemplo la indicación a que ese patrimonio "se transmite de generación en generación, es recreado constantemente por las comunidades y grupos en función de su entorno, su interacción con la naturaleza y su historia, infundiéndoles un sentimiento de identidad y continuidad y contribuyendo así a promover el respeto de la diversidad cultural y la creatividad humana", y también una indicación al límite al patrimonio inmaterial en los "instrumentos internacionales de derechos humanos existentes y con los imperativos de respeto mutuo entre comunidades, grupos e individuos y de desarrollo sostenible". Aunque en la relación de principios que hace la ley en el artículo 3 existen cuestiones similares o que aglutinan estas, y no hay que olvidar además que la Convención es aplicable en España.

Como decíamos anteriormente el artículo 2 de la ley española contiene una lista abierta de las manifestaciones del patrimonio inmaterial repartidas en 9 letras:

a. Tradiciones y expresiones orales, incluidas las modalidades y particularidades lingüísticas como vehículo del patrimonio cultural inmaterial; así como la toponimia ${ }^{3}$ tradicional como instrumento para la concreción de la denominación geográfica de los territorios;

b. artes del espectáculo;

c. usos sociales, rituales y actos festivos;

d. conocimientos y usos relacionados con la naturaleza y el universo ${ }^{4}$;

e. técnicas artesanales tradicionales;

f. gastronomía, elaboraciones culinarias y alimentación;

g. aprovechamientos específicos de los paisajes naturales ${ }^{5}$;

\footnotetext{
${ }^{2}$ Esta forma elegida para la definición la hemos podido ver también en una ley regional del entorno europeo, como es la Legge Regionale 23 ottobre 2008, n. 27 Valorizzazione del patrimonio culturale immateriale de la región italiana de Lombardía, o la Ley portuguesa.

${ }^{3}$ Durante el debate parlamentario el Grupo Socialista presentó una enmienda para incluir la toponimia, una propuesta que partía de la Real Academia Galega "referida al tesoro patrimonial que constituye la toponimia tradicional y solicitando su inclusión expresa en la definición de concepto de patrimonio cultural inmaterial".

${ }^{4}$ El Consejo de Estado propuso coordinar este apartado, "aun cuando se trata de una reproducción literal de la Convención de 2003. Téngase en cuenta que ésta ya se ha visto superada por el Protocolo de Nagoya de 2010 sobre acceso a recursos genéticos y a los conocimientos tradicionales asociados a los mismos (...), así como por las negociaciones en curso en el seno de la Organización Mundial de la Propiedad Intelectual que prevé, con el objeto de proteger mejor los conocimientos tradicionales hoy en día regulados en España por el artículo 70 de las ley 42/2007, otras figuras de derechos sui generis de propiedad intelectual".

${ }^{5}$ El Consejo de Estado propuso integrar este apartado y el anterior en el referido a "técnicas artesanales".
} 
h. formas de socialización colectiva y organizaciones;

i. manifestaciones sonoras, música y danza tradicional ${ }^{6}$.

La diferencia con la Convención UNESCO es la inclusión en la ley española de la toponimia tradicional, la gastronomía, los aprovechamientos específicos de los paisajes naturales, las formas de socialización colectiva y organizaciones, y las manifestaciones sonoras, música y danza tradicional. Es cierto que tanto la redacción de la convención como del artículo 2 de la ley 10/2015 puede hacernos pensar en que estamos ante una lista abierta ${ }^{7}$ a la que se podrán añadir categorías, pero que aparece de modo ejemplificador.

\subsection{Límites en la legislación estatal}

A estos principios habría que añadirles los relacionados en el artículo 3, que podríamos agrupar en 3 categorías:

- Límites a la salvaguardia del patrimonio: los principios recogidos en las letras a), b), y j), recuerdan que la salvaguardia del patrimonio cultural inmaterial tendrá que estar en consonancia con "los principios y valores de la Constitución Española y el Derecho de la Unión Europea, en especial la libertad de expresión", "con el principio de igualdad y no discriminación" y en específicamente con el llamado "principio de igualdad de género", y con "la libertad de circulación establecida en la normativa vigente en materia de unidad de mercado". Son similares a los propuestos por la Convención de 2003, pero llegan a ser más específicos. La Convención señala los derechos humanos, pero la ley española subraya por ejemplo la igualdad y en especial a la igualdad de género y la libertad de mercado ${ }^{9}$. La Ley portuguesa en este sentido ha seguido más fielmente la redacción de la Convención y así en su artículo 1.3 podemos leer:

"Para efeitos de aplicação do presente decreto -lei, apenas se considera património cultural imaterial o patrimonio que se mostre compatível com as disposições nacionais e internacionais que vinculem o Estado Português em matéria de direitos humanos, bem como com as exigências de respeito mútuo entre comunidades, grupos e individuos"

- Protagonismo de las comunidades portadoras, reflejado en los principios de las letras c), d) y e), que recogen con esas palabras y con el recordatorio al principio de participación de comunidades, grupos y asociaciones (que casi todas las leyes autonómicas subrayan) y el principio de accesibilidad para hacer posible el conocimiento y disfrute de los bienes. En este sentido la ley portuguesa de 2009 coincide en su artículo 2.1 letras c), d) y e).

- Las características propias del patrimonio inmaterial que deben tenerse en cuenta a la hora de su salvaguardia (letras f, g, h e i): como es el ser reflejo de la diversidad cultural, su dinamismo, la inescindibilidad que en numerosas ocasiones se produce entre el patrimonio material e inmaterial, y la sostenibilidad del patrimonio inmaterial que en muchas ocasiones se muestra incompatible con los conceptos de industrialización y mercantilización aplicados.

\footnotetext{
${ }^{6}$ Algunos grupos, como el Grupo parlamentario Catalán, propusieron enmiendas para incluir una letra específica para las expresiones musicales, basadas en que "no siempre pueden incluirse dentro de las artes del espectáculo (...) las composiciones musicales y la ejecución instrumental, el cante individual, a dúo o en agrupaciones musicales tradicionales, los orfeones y los coros, pero también sonidos arraigados en la colectividad (percusión, sonidos asociados a actividades laborales, mascletás, tamborradas, mapas de sonidos, etc.) tal y como establece el Plan Nacional de Salvaguarda del Patrimonio Cultural Inmaterial".

${ }^{7}$ López Braco, 2004.

${ }^{8}$ Este último límite supone para Carrera Díaz una "alusiones a las intenciones explícitas y latentes de mercantilización de la cultura cuando se mencionan los principios generales de las actuaciones de salvaguarda. Parece que de todo puede "protegerse" el PCI menos del mercado" (Carrera, 2015, p. 23).

${ }^{9}$ En este sentido es interesante reseñar la sentencia C367/70 de la Corte Constitucional de Colombia, sobre la demanda de inconstitucionalidad contra los artículos $1^{\circ}$, parcial; $2^{\circ}$, parcial; 12, parcial; 22, parcial; 26, parcial; 31, parcial y 80, parcial de la ley 916 de 2004. En esta sentencia se perfila la participación de los niños en los espectáculos taurinos, popularmente conocidos en Colombia como "niños torerillos". En la sentencia se marca la edad de catorce años cumplidos, además de la observancia de las condiciones de tratados internacionales suscritos por Colombia que suponen la garantía de las condiciones de seguridad para los menores.
} 


\section{Comparación de definición y criterios de la convención UNESCO, Ley estatal y las leyes autonómicas}

Las legislaciones autonómicas sobre patrimonio cultural se han ido desarrollando desde el año 1990, y la mayoría de ellas sólo contaba como bagaje previo con la pionera (y en ocasión imperfecta, como hemos visto más arriba) ley de Patrimonio Histórico Español de 1985, algún trabajo de UNESCO y aún quedaban años hasta la Convención de Patrimonio Inmaterial. Vamos a ver sus definiciones propuestas del patrimonio inmaterial (ya sea refiriéndose como tal o a través de las fórmulas del patrimonio etnológico o etnográfico) donde encontramos algunas cuestiones a destacar.

Los conceptos más usados son "conocimientos", "actividades", "usos", "costumbres" y "técnicas". Llama la atención que el término "manifestación", elegido para designar los bienes inmateriales en la ley de 2015, se usa en cinco legislaciones autonómicas (Cataluña, Asturias, Castilla y León, Murcia, y Castilla La Mancha). También es importante subrayar que solo cinco legislaciones (Navarra, Extremadura, Cantabria, Canarias y La Rioja) apuntan en la definición alguna alusión a la lengua o habla, y también solo siete (Baleares, Aragón, Cataluña, Canarias, Cantabria, La Rioja y Asturias) incluyen el soporte material de este patrimonio, pero cuatro de ellos solo asociado a un determinado tipo de bien. En cuanto a la definición los términos utilizados son (Tabla 1):

Tabla 1. Términos utilizados en las legislaciones autonómicas

\begin{tabular}{|c|c|}
\hline Términos & Legislación \\
\hline Actividades & $\begin{array}{l}\text { Cataluña, Galicia, Canarias, Asturias, Castilla y León, La Rioja, Navarra, Murcia, } \\
\text { Andalucía }\end{array}$ \\
\hline Comportamientos & País Vasco, Baleares, Aragón, Extremadura \\
\hline Conocimientos & $\begin{array}{l}\text { Cataluña, Galicia, Cantabria, Comunidad Valenciana, Canarias, Asturias, Castilla y } \\
\text { León, La Rioja, Navarra, Murcia }\end{array}$ \\
\hline Costumbres & País Vasco, Baleares, Aragón, Extremadura, Asturias, Murcia \\
\hline Creaciones & Baleares, Comunidad Valenciana, Aragón, Extremadura \\
\hline Creencias & La Rioja \\
\hline Expresiones & Andalucía, Madrid \\
\hline Formas de vida & Cataluña, Extremadura \\
\hline Funciones & La Rioja \\
\hline $\begin{array}{l}\text { Lenguas, habla, } \\
\text { peculiaridades lingüísticas }\end{array}$ & Navarra, Extremadura, Cantabria, Canarias, La Rioja \\
\hline Manifestaciones & Cataluña, Asturias, Castilla y León, Murcia, Castilla La Mancha \\
\hline Oficios & Cataluña \\
\hline Representaciones & Murcia \\
\hline Saberes & Cantabria, La Rioja, Andalucía \\
\hline $\begin{array}{l}\text { Soporte material } \\
\text { Técnicas }\end{array}$ & Baleares, Aragón, Cataluña, Canarias, Cantabria, La Rioja, Asturias \\
\hline Trabajos & Cataluña, Comunidad Valenciana, Canarias, La Rioja, Navarra, Murcia \\
\hline Tradición oral & Castilla y León \\
\hline Usos & Extremadura \\
\hline
\end{tabular}

Fuente: Elaboración propia

\subsection{Criterios de valorización}

En esas mismas definiciones podemos encontrar algunos criterios de valoración del patrimonio (Tabla 2). Entre ellos destaca claramente la relevancia para lo "tradicional" del territorio respectivo, criterio que podría asimilarse a "formar parte del acervo cultural", "pertenencia al territorio", "relevancia para la cultura popular", "para la memoria colectiva", "para la identidad (con el complemento de nacional o no)", "para los modos del pueblo". Cuatro legislaciones (Cantabria, Asturias, Castilla y León y Madrid) plantean la necesidad de que sean de transmisión consuetudinaria. Tres (Baleares, Madrid y Castilla La Mancha) que se trate de patrimonio vigente o vivo, mientras que solo una recuerda que 
pueden serlo también los bienes desaparecidos. También se podría subrayar que sólo Asturias plantea que deban ser bienes de desarrollo colectivo, y sólo Castilla y León plantea que sean elemento de vinculación y es la única que hace referencia a que así lo perciban los miembros de esa colectividad. País Vasco, que no plantea ningún criterio en su definición, sí incluye una posibilidad que es que este patrimonio puede superar el límite geográfico-político.

Tabla 2. Criterios de valorización

\begin{tabular}{|c|c|}
\hline Criterio & Legislación \\
\hline Desarrollo colectivo & Asturias \\
\hline Desaparecidos & Baleares \\
\hline Elemento de vinculación o relación social & Castilla y León \\
\hline En las que se reconozca un colectivo & Castilla y León \\
\hline Forman parte del acervo cultural & Cantabria \\
\hline Interés histórico & Asturias \\
\hline Pertenencia al territorio & Extremadura \\
\hline Potenciar el uso de la lengua & Comunidad Valenciana \\
\hline Puede sobrepasar el límite político-geográfico & País Vasco \\
\hline Relevancia para la cultura popular & Cataluña \\
\hline Relevancia para la identidad nacional & Cataluña \\
\hline Relevancia para la memoria colectiva & Cataluña, Baleares \\
\hline Relevancia para la tradición o lo tradicional & $\begin{array}{l}\text { Cataluña, Galicia, Comunidad Valenciana, Aragón, Canarias, } \\
\text { Asturias, Castilla y León, La Rioja, Navarra, }\end{array}$ \\
\hline Relevancia para los modos del pueblo respectivo & Galicia, Baleares, Aragón, Canarias, Navarra \\
\hline Transmisión consuetudinaria & Cantabria, Asturias, Castilla y León, Madrid \\
\hline Vigente, vivo & Baleares, Madrid, Castilla La Mancha \\
\hline
\end{tabular}

\subsection{Comparativa definición de PCI de UNESCO, ley PCI 2015, y legislaciones autonómicas}

\begin{tabular}{llll}
\hline & Convención UNESCO (2003) & $\begin{array}{l}\text { Ley de Patrimonio Cultural } \\
\text { Inmaterial (2015) }\end{array}$ & Legislaciones autonómicas \\
\hline Definición & Los usos, representaciones, expresiones, & Los usos, & Los conceptos más usados \\
& conocimientos y técnicas -junto con los & representaciones, & son conocimientos, \\
& instrumentos, objetos, artefactos, y & expresiones, & actividades, \\
& espacios culturales que le son inherentes- & conocimientos y & costumbres y técnicas ${ }^{10}$.
\end{tabular}

Criterios de Tradicional, contemporáneo y viviente a un valorización mismo tiempo; integrador; representativo; y basado en la comunidad: "que las comunidades, los grupos y en algunos casos los individuos reconozcan como parte integrante de su patrimonio cultural'".
Que las comunidades, los grupos y en algunos casos los individuos, reconozcan como parte integrante de su patrimonio cultural.
Entre ellos destaca claramente la relevancia para lo "tradicional" del territorio respectivo ${ }^{11}$.

\footnotetext{
${ }^{10}$ Siete legislaciones (Baleares, Aragón, Cataluña, Canarias, Cantabria, La Rioja y Asturias) incluyen el soporte material de este patrimonio.

${ }^{11}$ Cuatro legislaciones (Cantabria, Asturias, Castilla y León, Madrid) plantean la necesidad de que sean de transmisión consuetudinaria. Tres (Baleares, Madrid y Castilla La Mancha) que se trate de patrimonio vigente o vivo, mientras que solo una (Baleares) recuerda que pueden serlo también los bienes desaparecidos. Solo Castilla y León señala que sea un patrimonio que signifique un elemento de vinculación social.
} 


$\begin{array}{llll}\begin{array}{l}\text { Ámbitos o listas } \\ \text { ejemplificativas }\end{array} & \mathrm{Si}^{12} & \mathrm{Si}^{13} & \mathrm{Si} \\ \end{array}$

Fuente: Elaboración propia

\section{Desafíos para una prospectiva investigadora}

De la legislación vigente en España, sólo la convención UNESCO y la Ley estatal tienen referencias a los límites del patrimonio cultural inmaterial. Límites que será necesario perfilar porque por la propia definición de PCI tan extensa, irremediablemente habrá choques y contradicciones con otros derechos.

Por tanto, es un desafío que deberemos aceptar, y que doctrina y jurisprudencia deben ayudar a clarificar, para poder tener una efectiva salvaguardia del Patrimonio Cultural Inmaterial, sin que ello suponga ninguna situación injusta.

\section{Referencias}

Carrera Díaz, G. (2009). Iniciativas para la salvaguardia del Patrimonio Inmaterial en el contexto de la Convención UNESCO, 2003: una propuesta desde Andalucía. Patrimonio Cultural de España, 0, 181.

Carrera Díaz, G. (2015). La ley 10/2015 para la salvaguarda del PCI (2013-2014): ¿patrimonio inmaterial o nacionalismo de Estado?. Revista PH Panorama, 88, 23. Instituto Andaluz del Patrimonio Histórico

González Cambeiro, S., y Querol, M. A. (2014). El patrimonio inmaterial. Madrid: Catarata.

López Bravo, C. (2004). El patrimonio cultural inmaterial en la legislación española. Una reflexión desde la Convención de la UNESCO de 2003. Patrimonio Cultural y Derecho, 8. Madrid: Hispania Nostra.

Ministerio de Cultura. (2011). Plan Nacional de Salvaguarda del Patrimonio Cultural Inmaterial. Disponible en $\mathrm{http} / /$ ipce.mcu.es/conservacion/planesnacionales/inmaterial.html

Prieto de Pedro, J. (2002). La protección jurídica del folclore. En Influencia y legado español en las culturas tradicionales de los Andes americanos. Memorias. III Encuentro para la promoción y difusión del patrimonio folclórico de los países andinos. Granada, España, octubre de 2002. Bogotá: Convenio Andrés Bello.

Roque, M. (2013). Un patrimonio vivo y dinámico. Intangible cultural heritage and memory. Quaderns de la Mediterrània, $13,178$.

Vaquer Caballería, M. (2005). La protección jurídica del patrimonio inmaterial. Museos.es. Revista de la Subdirección General de Museos Estatales, 1.

\footnotetext{
${ }^{12}$ Las tradiciones y expresiones orales, incluido el idioma como vehículo del patrimonio cultural inmaterial. Las artes del espectáculo. Los usos sociales, rituales y actos festivos. Los conocimientos y usos relacionados con la naturaleza y el universo. Las técnicas artesanales tradicionales.

${ }^{13}$ Tradiciones y expresiones orales, incluidas las modalidades y particularidades lingüísticas como vehículo del patrimonio cultural inmaterial; así como la toponimia tradicional como instrumento para la concreción de la denominación geográfica de los territorios. Artes del espectáculo. Usos sociales, rituales y actos festivos. Conocimientos y usos relacionados con la naturaleza y el universo. Técnicas artesanales tradicionales. Gastronomía, elaboraciones culinarias y alimentación. Aprovechamientos específicos de los paisajes naturales. Formas de socialización colectiva y organizaciones. Manifestaciones sonoras, música y danza tradicional.

${ }^{14}$ Algunas legislaciones también incluyen listas abiertas a modo de ejemplo o para completar las definiciones. Tal es el caso de Cataluña, Cantabria, Baleares, Valencia, Canarias, Asturias, La Rioja y Madrid. Entre ellas, Canarias y La Rioja hacen referencia expresa a la toponimia. Entre los ejemplos destaca en cuanto a número de menciones la música, el baile, los juegos deportes y fiestas.
} 